\title{
Morbidity pattern and health-seeking behavior among the senior citizens in a selected urban area of Bangladesh: A cross-sectional study
}

\author{
Rajat Das Guptal, Avijit Loha², Saikat Roy ${ }^{3}$
}

1,3 Intern Doctor, Dhaka Medical College Hospital, Dhaka Bangladesh. ${ }^{2}$ Assistant Surgeon, Government of the Peoples Republic of Bangladesh; Medical Officer, Mirzaganaj Upazilla Health Complex, Patuakhali, Bangladesh.

\begin{abstract}
Elderly people suffer from different morbidities as the increase in prevalence of disease is proportionate to increasing age. In Bangladesh, the number of the elderly person is increasing with time. This study aims to determine the morbidity pattern and health seeking behavior among the urban senior citizens of Bangladesh. A cross -sectional study was carried out from January 2014 to December 2014 in different areas of Dhaka City. Information was collected from 384 respondents, aged 60 years and above by purposive sampling technique. The mean age of the study population was $64.7(\mathrm{SD} \pm 5.7)$ years and majority $(74.74 \%)$ belonged to $60-69$ years age group. More than half $(52.6 \%)$ of the respondents were female. Most of the respondents $(71.61 \%)$ received institutional education; $51.82 \%$ of the elderly were still working; $63 \%$ of the respondents were totally independent; $11.74 \%$ were totally dependent; and $53.65 \%$ respondents belonged to joint family. Most of the respondents (96.8\%) were suffering from at least one medical problem; the commonest was musculoskeletal problems $(84.11 \%)$ followed by eye problems $(81.25 \%)$. Majority of male $(78.8 \%)$ and females $(89.60 \%)$ were suffering from eye problems and musculoskeletal problems respectively. All the respondents sought treatment for their health problems. Majority $(33 \%)$ respondents went to government hospitals for medical help. Most of the male $(68.70 \%)$ and female $(71.26 \%)$ can do their daily physical activities without any problem. Approximately $30 \%$ respondents did health check-up once in one year. Majority respondents took prescribed medications (69.27\%) and were satisfied with their treatment $(56.77 \%)$. The study findings showed that urban geriatric population had one or more morbidities and their health seeking behavior was poor, more among females. The study concludes with further emphasis of primary health care for the urban elderly people of Bangladesh. The health care service should be accessible and affordable to the elderly people.
\end{abstract}

Keywords: Senior citizens, Urban elderly, Morbidity, Health seeking behavior, Bangladesh.

\section{Introduction}

We all know that aging is a natural process. ${ }^{1}$ According to Seneca, 'Old age is an incurable disease.' 2 The proportion of older persons is increasing; compromised $7 \%$ of the world population in 1950 and $11 \%$ in 2007 ; and it has been estimated that it will rise to $22 \%$ in the year $2050 .^{3}$ The growth rate of population of older persons is of $2.6 \%$ per year. It is considerably faster than the population as a whole which is increasing at $1.1 \%$ annually. ${ }^{4}$ It has been estimated that there will be one billion persons in the world whose age will be $\geq 65$ years and $7 \%$ of them will reside in the low-income countries. ${ }^{5}$

Bangladesh cannot be an exception. There were 7.8 million elderly persons in 2001 in Bangladesh and it has been estimated that this number will turn into 16.2 million by $2025 .^{6}$ This country is now in a state of both epidemiologic and demographic transitions. As a result both fertility and mortality rates in early life will reduce. These results will increase life expectancy to 74 years in $2025 .^{3}$

Prevalence of disease increases with increased age. Chronic health conditions are common in these ages and lead to multiple morbidities. Most common of these

\section{Practice Points}

- The worldwide increase in the aging population has huge implications on social and health care.

- The study findings showed that urban geriatric population had one or more morbidities and their health seeking behavior was poor, more among females.

- Most of the respondents were suffering from at least one medical problem; the commonest was musculoskeletal problems followed by eye problems.

- All of the respondents sought treatment for their health problems; one-third elderly went to government hospitals for medical help.

- Emphasis should be given to establish primary health care for the urban elderly people of Bangladesh.

conditions are hypertension, diabetes, arthritis, heart diseases, cancer and sinusitis. ${ }^{3,7}$ In the developed countries a lot of studies have been performed to find

Correspondence: Dr. Rajat Das Gupta, Intern Doctor, Dhaka Medical College Hospital, Dhaka Bangladesh. E-mail: rajat89.dasgupta@gmail.com. 
out the pattern of multi-morbidity among older persons. ${ }^{8}$ But in developing countries there are few studies. In 2003, Joshi et al. ${ }^{8}$ reported that $83 \%$ of the elderly people had more than three morbidities in India. In 2013 Sharma et al. ${ }^{9}$ reported that the most common morbidity among aged population of Shimla district in Himachal Pradesh, India was musculoskeletal problems $(55.0 \%)$ followed by hypertension $(40.5 \%)$. In China, $21.7 \%$ of rural elderly people have at least two morbidities, and $15.9 \%$ have three or more morbidities. ${ }^{10}$ Unfortunately little is known about the prevalence of morbidity among elderly persons in urban Bangladesh. Distribution of chronic conditions and multimorbidity couldn't be known due to little information. ${ }^{11}$

In Bangladesh, the elderly people suffer from both communicable as well as non-communicable disease. The chronic illnesses usually include hypertension, coronary heart disease, and cancer. ${ }^{11}$ In addition, there is impairment of vision and hearing and decline in immunity. ${ }^{12}$ The prevalence of tuberculosis is higher among the elderly than younger individuals. ${ }^{13}$ Obesity and its complications are common in elderly people of middle and higher income groups. This is due to sedentary lifestyle and decreased physical activity. Dementia, mood disorders, neurotic and personality disorders, drug and alcohol abuse, delirium, and mental psychosis are the most common psychological disorders seen in this age group. ${ }^{12}$

Breakdown in family values and the framework of family support has been occurring in recent ages and the reason is rapid urbanization and societal modernization. In addition, financial insecurity, social isolation and abuse lead to development of psychological illnesses. Widows are prone to face isolation from the society. ${ }^{12}$

With the increasing number of elderly population there is an increasing need for comprehensive geriatric care at community level. ${ }^{4}$ To organize effective services, information base need to be developed about different aspect of elderly population. But there have not been adequate info about the health-seeking behavior of the elderly people in the urban areas of Bangladesh.

The government should also effectively plan health care services for the elderly and prepare a feasible implementation design relevant to the needs of country. There is absence of facilities for medical treatment and organizations for providing economic and social support for the aging population. For planning the health care facilities for the aging population the information $\mathrm{n}$ the morbidity patterns has to be known. ${ }^{14}$

This study aims to find out the morbidity pattern and health seeking behavior among the senior citizens in a selected urban area of Bangladesh.

\section{Materials and methods}

This descriptive cross-sectional study was conducted from January 2014 to December 2014 in Mohammadpur, Dhanmondi and Jhighatala area of the
Dhaka City (the capital of Bangladesh). The site was selected due to people of all socio-economic conditions reside in that place. The study population were senior citizens aged 60 years and above of both sexes. After extensive literature review, due to lack of information on morbidity and health seeking among senior citizens in the study area, we assumed the prevalence is $50 \%$. Assuming a confidence level of $95 \%$, the sample size was calculated 384 .

The respondents were selected by purposive sampling. Data was collected by face to face interview of the respondents with the help of a pretested semi-structured interview schedule. There were two parts; questions related to socio demographic characteristics and questions related to morbidity pattern and health seeking behavior. Morbidity patterns were confirmed by seeing the hospital records of the patients. Written informed consent was taken from the respondents. The questionnaire was validated (unpublished data) and a biostatistician was consulted. Written informed consent was taken from the respondents. Data entry was made in Microsoft Office Excel software in codes and analysis was done by SPSS software version 14.0. Descriptive statistical analysis, which included frequency, mean and percentages, was used to characterize the data.

Approval for this study was obtained from Dhaka Medical College Ethics Committee. The authors followed the recommendations of the Strengthening the Reporting of Observational Studies in Epidemiology (STROBE) Statement in preparing this manuscript. ${ }^{15}$

\section{Results}

The mean age of the respondents was $64.7(\mathrm{SD} \pm 5.7)$ years and majority $(74.74 \%)$ belonged to $60-69$ years age group. More than half $(52.6 \%)$ of the respondents were female and $60.94 \%$ wer currently married and rest were widowed. Most of the respondents (71.61\%) received institutional education. More than half $(51.82 \%)$ of the elderly were still working. Regarding economical status, $63 \%$ of the respondents were totally independent and $11.74 \%$ were totally dependent. 206 $(53.65 \%)$ respondents belonged to joint family (Table $1)$.

Most of the respondents (96.8\%) were suffering from at least one medical problem. Majority $(84.11 \%)$ of the respondents were suffering from musculoskeletal problems followed by eye problem $(81.25 \%)$ and hearing problem $(70.05 \%)$, gastrointestinal disorders (70.59\%), and insomnia (70.05\%). Among female, majority were suffering from musculoskeletal problems $(89.60 \%)$ and eye problems $(82.67 \%)$. In case of male population, majority were suffering from eye problems $(78.80 \%)$ and musculoskeletal problems $(78.02 \%)$ (Table 2).

It was found that all $(100 \%)$ of the respondents sought treatment for their health problems. Among them, 33\% respondents went to government hospitals for their problems and $25 \%$ visited private hospitals (Figure 1). 
Table 1: Socio-demographic profile of the study population

\begin{tabular}{|c|c|c|c|}
\hline Category & $\begin{array}{c}\text { Male (\%) } \\
(n=182)\end{array}$ & $\begin{array}{c}\text { Female }(\%) \\
(n=202)\end{array}$ & Total $(\%)(n=384)$ \\
\hline \multicolumn{4}{|l|}{ Age group } \\
\hline $60-69$ years & $138(75.82 \%)$ & $149(73.76 \%)$ & $287(74.74 \%)$ \\
\hline 70-79 years & $32(17.58 \%)$ & $35(17.33 \%)$ & $67(17.45 \%)$ \\
\hline More than 80 years & $12(6.6 \%)$ & $18(8.91 \%)$ & $30(7.81 \%)$ \\
\hline Gender & $182(47.4 \%)$ & $202(52.6 \%)$ & $384(100 \%)$ \\
\hline \multicolumn{4}{|l|}{ Religion } \\
\hline Islam & $145(43.28 \%)$ & $190(56.72 \%)$ & $335(87.23 \%)$ \\
\hline Hinduism & $34(73.91 \%)$ & $12(26.09 \%)$ & $46(12.762 \%)$ \\
\hline Christianity & $3(100 \%)$ & $0(0 \%)$ & $3(.008 \%)$ \\
\hline \multicolumn{4}{|l|}{ Education } \\
\hline Illiterate & $10(13.89 \%)$ & $62(86.11 \%)$ & $72(19.53 \%)$ \\
\hline Non-institutional & $9(24.32 \%)$ & $28(75.68 \%)$ & $37(8.86 \%)$ \\
\hline Institutional & $163(59.27 \%)$ & $112(40.73 \%)$ & $275(71.61 \%)$ \\
\hline \multicolumn{4}{|l|}{ Occupation } \\
\hline Work & $134(67.34 \%)$ & $65(32.66 \%)$ & $199(51.82 \%)$ \\
\hline Do not work & $48(25.95 \%)$ & $137(74.05 \%)$ & $185(48.18 \%)$ \\
\hline \multicolumn{4}{|l|}{ Marital Status } \\
\hline Married & $131(55.98 \%)$ & $103(44.02 \%)$ & $234(60.94 \%)$ \\
\hline Widowed & $51(34 \%)$ & $99(66 \%)$ & $150(39.06 \%)$ \\
\hline \multicolumn{4}{|l|}{ Family type } \\
\hline Nuclear Family & $105(57.70 \%)$ & $73(36.14 \%)$ & $178(46.35 \%)$ \\
\hline Joint Family & $77(42.30 \%)$ & $129(63.86 \%)$ & $206(53.65 \%)$ \\
\hline \multicolumn{4}{|l|}{ Economic condition } \\
\hline Totally independent & $95(52.20 \%)$ & $147(72.77 \%)$ & $242(63 \%)$ \\
\hline Partially dependent & $56(30.77 \%)$ & $41(20.30 \%)$ & $97(25.26 \%)$ \\
\hline Totally dependent & $31(17.03 \%)$ & $14(6.93 \%)$ & $45(11.74 \%)$ \\
\hline
\end{tabular}

Table 2: Morbidity patterns of the respondents

\begin{tabular}{|l|c|c|c|}
\hline \multicolumn{1}{|c|}{ Health problems } & Male (n=182) & Female (n=202) & Total (n=384) \\
\hline Eye problem & $145(78.80 \%)$ & $167(82.67 \%)$ & $312(81.25 \%)$ \\
\hline Hearing problem & $113(62.08 \%)$ & $156(77.23 \%)$ & $269(70.05 \%)$ \\
\hline Psychological distress & $18(9.89 \%)$ & $35(17.33 \%)$ & $53(13.80 \%)$ \\
\hline Respiratory problem & $89(48.90 \%)$ & $56(27.72 \%)$ & $145(37.76 \%)$ \\
\hline Pulmonary Tuberculosis & $21(11.54 \%)$ & $30(14.85 \%)$ & $51(13.28 \%)$ \\
\hline Musculo-skeletal disorder & $142(78.02 \%)$ & $181(89.60 \%)$ & $323(84.11 \%)$ \\
\hline Hypertension & $71(39.01 \%)$ & $50(24.75 \%)$ & $121(31.51 \%)$ \\
\hline Ischemic Heart Disease & $25(13.74 \%)$ & $6(2.97 \%)$ & $31(8.07 \%)$ \\
\hline Gastrointestinal disorder & $120(65.93 \%)$ & $151(74.75 \%)$ & $271(70.59 \%)$ \\
\hline Genito-urinary problem & $34(18.68 \%)$ & $46(22.77 \%)$ & $80(20.83 \%)$ \\
\hline Diabetes mellitus & $57(31.31 \%)$ & $37(18.32 \%)$ & $94(24.48 \%)$ \\
\hline Cancer & $8(4.40 \%)$ & $20(9.91 \%)$ & $28(7.29 \%)$ \\
\hline Dermatological problems & $49(26.92 \%)$ & $66(32.67 \%)$ & $115(29.95 \%)$ \\
\hline Insomnia & $122(67.03 \%)$ & $147(72.77 \%)$ & $269(70.05 \%)$ \\
\hline $\begin{array}{l}\text { Others (parkinsonism, Alzheimer's } \\
\text { disease, oral ulcer etc.) }\end{array}$ & $11(6.04 \%)$ & $14(6.93 \%)$ & $25(6.51 \%)$ \\
\hline
\end{tabular}

Majority of male (68.70\%) and female (71.26\%) respondents were able to do their daily physical activities without any problem (Figure 2).

Approximately $29 \%$ of the respondents did health check -up once in a year, $28.13 \%$ respondents did once in three months, and $69.27 \%$ respondents took prescribed medications. Among those who did not take regular medication, $38.98 \%$ did not do it because of increase cost of the drugs. It was also found that more than half of the $(56.77 \%)$ of the respondents were satisfied with their treatment. The causes of non-satisfaction were expense of medicine $(36.14 \%)$, poor attitude of the health workers $(31.32 \%)$, unavailability of the health workers $(19.28 \%)$, and inaccessibility of the health care system (10.84\%) (Table 3).

\section{Discussion}

The current study finds out that most of the respondents $(96.8 \%)$ were suffering from at least one medical 
Table 3: Health seeking behavior of the respondents

\begin{tabular}{|l|c|c|c|}
\hline \multicolumn{1}{|c|}{ Category } & \multicolumn{3}{c|}{ Frequency (\%) } \\
\hline Frequency for check-up & Male $(\%)(\mathrm{n}=182)$ & Female $(\%)(\mathrm{n}=202)$ & Total $(\%)(\mathrm{n}=384)$ \\
\hline Once a month & $24(12.19 \%)$ & $23(11.38 \%)$ & $47(12.23 \%)$ \\
\hline Once in 3 months & $61(33.53 \%)$ & $47(23.27 \%)$ & $108(28.13 \%)$ \\
\hline Once in 6 months & $32(18.57 \%)$ & $66(32.67 \%)$ & $98(25.52 \%)$ \\
\hline Once in a year & $54(29.67 \%)$ & $59(29.21 \%)$ & $113(29.43 \%)$ \\
\hline Irregular & $11(6.04 \%)$ & $7(3.47 \%)$ & $18(4.69 \%)$ \\
\hline Don't visit & $0(0 \%)$ & $0(0 \%)$ & $0(0 \%)$ \\
\hline Regularity of taking prescribed treatment & Male $(\%)(\mathrm{n}=182)$ & Female $(\%)(\mathrm{n}=202)$ & Total $(\%)(\mathrm{n}=384)$ \\
\hline Yes & $127(69.78 \%)$ & $139(68.81 \%)$ & $266(69.27 \%)$ \\
\hline No & $55(30.22 \%)$ & $63(31.19 \%)$ & $118(30.73 \%)$ \\
\hline Irregularity of taking prescribed treatment & Male $(\%)(\mathrm{n}=55)$ & Female $(\%)(\mathrm{n}=63)$ & Total $(\%)(\mathrm{n}=118)$ \\
\hline Medicines are expensive & $19(34.55 \%)$ & $27(42.86 \%)$ & $46(38.98 \%)$ \\
\hline Consider them unnecessary & $22(40 \%)$ & $19(30.16 \%)$ & $41(34.75 \%)$ \\
\hline Don't get them nearby & $14(25.45 \%)$ & $17(26.98 \%)$ & $31(26.27 \%)$ \\
\hline Satisfaction with available healthcare system & Male $(\%)(\mathrm{n}=182)$ & Female $(\%)(\mathrm{n}=202)$ & Total $(\%)(\mathrm{n}=384)$ \\
\hline Satisfied & $107(58.79 \%)$ & $111(54.95 \%)$ & $218(56.77 \%)$ \\
\hline Not Satisfied & $75(41.21 \%)$ & $91(45.05 \%)$ & $166(43.23 \%)$ \\
\hline Not satisfied with available healthcare system & Male $(\%)(\mathrm{n}=75)$ & Female $(\%)(\mathrm{n}=91)$ & Total $(\%)(\mathrm{n}=166)$ \\
\hline Health care system is far away & $4(5.33 \%)$ & $14(15.38 \%)$ & $18(10.84 \%)$ \\
\hline Poor attitude of healthcare providers & $32(42.67 \%)$ & $20(21.98 \%)$ & $52(31.32 \%)$ \\
\hline Service providers were not always available & $16(21.33 \%)$ & $16(17.58 \%)$ & $32(19.28 \%)$ \\
\hline Medicines were expensive & $23(30.67 \%)$ & $37(40.66 \%)$ & $60(36.14 \%)$ \\
\hline Medicines were not available & $0(0 \%)$ & $4(4.4 \%)$ & $4(2.42 \%)$ \\
\hline
\end{tabular}

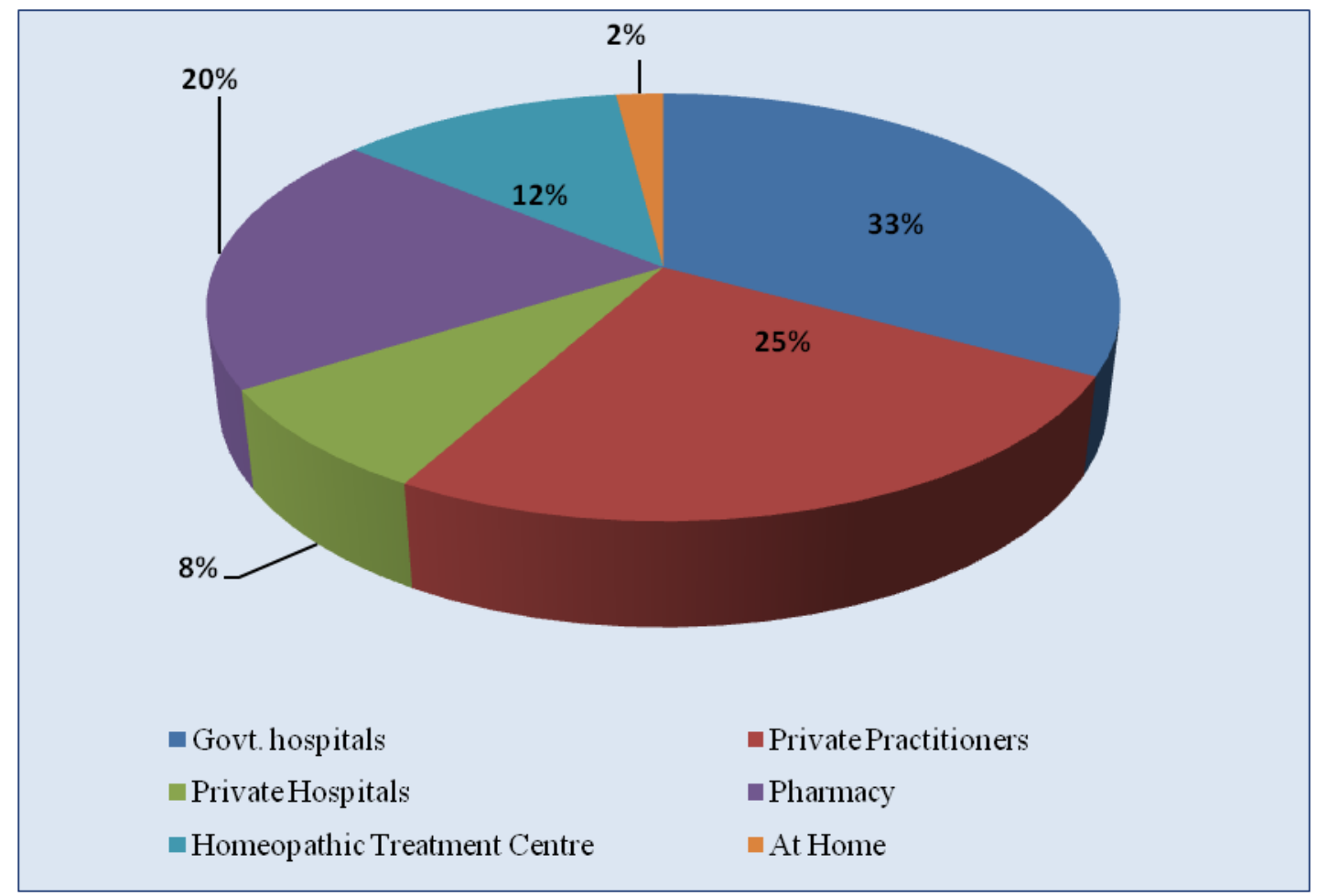

Figure 1: Place of seeking treatment for health problems

problem. This result accords with findings of Jabeen et $a{ }^{3}{ }^{3}$ where almost all $(98.8 \%)$ had one or more health problems. Among those who had mortalities 19.7\% had at least one morbidity, $16.3 \%$ had two morbidities, had $53.5 \%$ three morbidities, and $10.5 \%$ had four to six morbidities. Sharma et al. ${ }^{9}$ found in their study that $15.3 \%$ had one morbidity, $25.5 \%$ had two morbidities, $19.7 \%$ had three morbidities, and $23.5 \%$ had four to six morbidities.
The mean age of the respondents was 64.7 years and nearly three-fourth belonged to the age group of 60-69 years. This finding are similar to the findings of Jabeen et $a l^{3}$ conducted in Gazipur, Bangladesh were they found that nearly two-thirds belonged to age group of 60-64 years with mean age of 64.2 years. Current study finds out that majority of the respondents were female. Almost three-fifth of the respondents was currently married. These findings differ with the national findings 




Figure 2: Performance of physical activities

of Bangladesh. There could be the predominance of male, and young senior citizens. ${ }^{6}$

In our study, nearly three-fourths of the respondents received education (institutional/non institutional). This finding differs from the findings of Jabeen et al. ${ }^{3}$ which reported that nearly half of the respondents were illiterate. This discrepancy was due to place of the study as our study was based at the centre of the Dhaka city and the other one in the semi-urban Gazipur area located outside of Dhaka city.

In our study, we found that more than half of the elderly were still at work, half of them belonged to joint family, having 4-6 family members and majority were the followers of Islam. These findings are consistent with national statistics of Bangladesh. ${ }^{6}$

Regarding morbidities, we have found that the most common morbidities among the both male and female population were eye problem, hearing problem, insomnia, gastro-intestinal problems, and musculoskeletal disorders. The prevalence of cardio-vascular disorders and dermatological problems were more among female population and respiratory problems, hypertension and diabetes mellitus were more prevalent among the males.

Jabeen et al. ${ }^{3}$ found that eye problems, hearing problem, musculoskeletal disorder, cerebrovascular disorder, gastrointestinal disorder, diabetes, dermatological problem and sleeping problems were more among females. On the other hand, problems such as respiratory and genitor-urinary are more prevalent in males. But oral lesions, tuberculosis and cancers were equally distributed. ${ }^{3}$ This discrepancy was probably due variation in time and place. Similar finding was found by Manandhar et al. ${ }^{16}$ In a study conducted among elderly people in Mumbai, India, where they found $43 \%$ diabetic, $47.7 \%$ hypertensive, and $68.2 \%$ visually impaired; all these were higher in the 70-79 years age group. ${ }^{16}$ While searching for the health status of the rural aged in Andhra Pradesh, India Rao et al. ${ }^{17}$ noticed that prevalent diseases included musculoskeletal $(80 \%)$, respiratory $(68 \%)$, sight $(44 \%)$ and dental conditions (40\%). Approximately four-fifths $\%$ of the respondents were functionally independent in activities of daily living. ${ }^{17}$ The variation with our study was due to geographical difference.

Musculo-skeletal problems were also reported as the commonest finding among elderly population in a study conducted in Shimla Hills of North India. ${ }^{18}$ A study from rural area of Rohtak district of Haryana, India reported that the leading symptoms among the male elderly were visual impairment $(65 \%)$, which supports the findings of our study. ${ }^{17} \mathrm{We}$ found the eye problem (78.8\%) as the most common morbidity among male elderly.

In our study the prevalence rate of diabetes mellitus was $24.48 \%$. In 2001, Jabeen et al. ${ }^{19}$ reported that among the elderly attending the Bangladesh Institute of Geriatric Medicine, $14.4 \%$ had diabetes mellitus. This discrepancy is may be due to time difference.

This is very encouraging that $100 \%$ of the respondents were seeking treatment for their health problems. This reveals their awareness of the community to improve their quality of life about their health. Sharma et al. ${ }^{9}$ reported that in Shimla Hills, only two third (65.8\%) were seeking treatment. This difference is probably due to geographical difference and accessibility of the health care services available in the area. 
In our study, we found that majority $29.43 \%$ respondents did health check-up once in one year followed by $28.13 \%$ respondents did health check-up once in three months. Only $4.69 \%$ subjects were irregular. A study in rural Bangladesh reported majority $(35 \%)$ of the subjects was irregular, $25 \%$ had check-up once in a year, and almost $19 \%$ did once in six months. ${ }^{3}$ This difference is probably due to increase health consciousness among the urban population and obviously this result is encouraging. This can also because of increase in availability and affordability of health care services in urban area.

About $70 \%$ elderly performed physical activity. This differs to the study conducted by Jabeen et al. ${ }^{3}$ where they found that $88.4 \%$ elderly performed physical activity, among them majority were male. This is may be due to the difference between urban and rural area (sedentary life style of urban population). In rural Andhra Pradesh was reported that more male compared to female could able to perform these tasks without others help. ${ }^{19}$

In our study, majority (33\%) of the respondents went to Govt. hospitals for health problems. Similar findings were found by Jabeen et al. ${ }^{3}$ They find that for illness showed that majority (31\%) preferred to go to Govt. hospitals. ${ }^{3}$ This is due to the cost of health care services in Govt. Hospitals of Bangladesh is cheap. It differs from the findings of Narapureddy et al. ${ }^{20}$ In a study conducted in rural UP, the authors found that $45.7 \%$ of the elderly persons sought treatment from private practitioner and private hospital, 32.3\% from quack. Only $18.9 \%$ sought treatment from Govt. hospitals. ${ }^{20}$ This discrepancy is may be due to lack of accessibility of Govt. health services in that reason.

The study had several limitations. First of all, there may be possibilities of recall bias. The sample was small and was drawn from one limited geographical area of urban Bangladesh. So, the results cannot be generalized to national population. Because of the cross-sectional design, this study had a limited explorative value. Baseline survey data related to this topic could not be available. Limited national and international studies were also found.

Purposive sampling was done, with a sample size of three hundred and eighty four. Due to small sample size, this study results may not have generalized acceptability. Another aspect can be mentioned as the samples were from the capital city, and the assessment may not be representative of the elderly who are devoted of modern facilities. So, this result may not be representative to the urban geriatric population of Bangladesh.

But still it is the first study done in the study area. More studies should be done in the future to find out the real picture of the morbidity pattern and health seeking behavior among the senior citizens in rural area of Bangladesh.

\section{Conclusion}

The worldwide increase in the aging population has huge implications on social and health care. Our study has shown that the prevalence of morbidity is high among the elderly population, particularly among the elderly women in urban Bangladesh. Action should be taken for equal distribution of health care among men and women. Geriatric clinics should be established and special service should be ensured for senior citizens in the hospitals. Also health education should be given at the earlier ages to prevent some diseases at the old age. More studies should be done at a larger scale in the future to find out the health seeking behavior and morbidity pattern of senior citizen of Bangladesh.

\section{Conflict of interest}

The authors declare no conflict of interest.

\section{References}

1. Park K. Park's Textbook of Preventive and Social Medicine. 20th ed. Prem Nagar, Jabalpur, India: M/s Banarsidas Bhanot, 2009.

2. Neeraja KP. Textbook of Growth and Development for Nursing Students. 1st ed. Jaypee Brothers Publishers, New Delhi, India, 2006.

3. Jabeen S, Bari MA, Wazib A, Umma S, Shaheduzzaman AKM, Das PP, et al. Morbidity pattern and health-seeking behavior among the senior citizens in selected rural areas of Bangladesh. J Dhaka Med Coll 2013; 22(2):12935.

4. Rashid KM, Rahman M and Hayder S. Textbook of Community Medicine \& Public Health. 4th Ed. Dhaka: RHM Publishers, 2009.

5. Solomons NW. Health and ageing. In: Flores R, Gillepsie S, editors. Health and nutrition: emerging and reemerging issues in developing countries. Washington DC: International Food Policy Research Institute, 2001.

6. Bangladesh Bureau of Statistics (BSS). Statistical Pocketbook of Bangladesh 2001. Dhaka: BSS, Planning Division, Ministry of Planning, Government of the People's Republic of Bangladesh, 2002

7. Adhikari D, Rijal DP. Factors Affecting Health Seeking Behavior of Senior Citizens of Dharan. $J$ Nobel Med Coll 204;3(1):50-7.

8. Joshi K, Kumar R, Avasthi A. Morbidity profile and its relationship with disability and psychological distress among elderly people in northern India. Int J Epidemiol 2003;32:978-87.

9. Sharma D, Mazta SR, Parashar A. Morbidity Pattern and Health-seeking Behavior of Aged Population residing in Shimla Hills of North 
India: A Cross-Sectional Study. J Family Med Prim Care 2013;2(2):188-93.

10. Zhou B, Chen K, Wang J, Wang H, Zhang S, Zheng W. Quality of life and related factors in the older rural and urban Chinese populations in Zhejiang province. $J$ Appl Gerontol 2011;30:199 -225 .

11. Khanam M A, Streatfield P K , Kabir Z N , Qiu $\mathrm{C}$, Cornelius C, and Åke Wahlin C. Prevalence and Patterns of Multimorbidity among Elderly People in Rural Bangladesh: A Cross-sectional Study. J Health Popul Nutr 2011;29(4):406-14

12. Ingle GK, Nath A. Geriatric Health in India: Concerns and Solution. Indian J Community Med 2008; 33(4): 214-218.

13. Negin J, Abimbola S, Marais BJ. Tuberculosis among older adults- time to take notice. Int $J$ Infect Dis 2015;32:135-7.

14. Kishore S, Juyal R, Senwal J, Chandra R. Morbidity profile of elderly persons. JK Science 2007;9(2);87-89.

15. Von Elm E, Altman DG, Egger M, Pocock SJ, Gotzsche PC, Vandenbroucke JP, et al. The Strengthening the Reporting of Observational Studies in Epidemiology (STROBE) statement: guidelines for reporting observational studies. Lancet 2007; 370(9596): 1453-7.
16. Manandhar MC, Anklesaria PS, Ismail SJ Weight, skinfolds and circumference characteristics of poor elderly people in Mumbai, India. Asia Pac J Clin Nutr 1997;6:191-9.

17. Venkateswarlu V, Iyer RSR, Rao KM (2003) Health status of the rural aged in Andhra Pradesh: A sociological perspective. Res Devlop $J$ 2003;9(2).

18. Bharati D R, Pal R P, Rekha R, Yamuna T V, Kar S. Ageing in Puducherry, South India: An overview of morbidity profile. $J$ Pharm Bioallied Sci 2011; 3(4): 537-42.

19. Jabeen S, Haque M A, Siddiqua SA, Hossain S, Jabber MA, Khan W. Self-health care among the elderly attending Bangladesh Institute of Geriatric Medicine, Dhaka. JOPSOM 2001;20 (1): 19-22.

20. Narapureddy B , Naveen KH, Madithati P, SinghR K, Pirabu RA. Socio-demographic Profile and Health Care Seeking Behavior of Rural Geriatric Population of Allahabad District of UP: A Cross Sectional Study. Int J Med Sci Public Health. 2012;1(2): 87-92. 